\title{
Age and baseline creatinine as risk factors for methotrexate nephrotoxicity in children with acute lymphoblastic leukemia in resource-limited countries
}

\author{
Itzel Anguiano ${ }^{1}$, Jose Leon ${ }^{1}$, and Ma. Ruiz ${ }^{1}$ \\ ${ }^{1}$ Secretaria de Salud del Estado de Guanajuato
}

September 25, 2021

\begin{abstract}
Introduction. The search for risk factors for high-dose methotrexate (MTX)-induced nephrotoxicity in children with acute lymphoblastic leukemia (ALL) has been complex in the context of resource-limited countries where serum levels of MTX are not always available. Objective. To analyze the demographic, clinical, and biochemical factors associated with MTX-induced nephrotoxicity in children with ALL. Methodology. Case-control study in children with ALL from a General Hospital in Mexico over a four-year period (2016-2020). Kidney damage was defined with KDIGO criteria and the following variables were analyzed: sex, age, weight, height, creatinine, urea, transaminases, hematic cytometry, vomiting, mucositis, dermatitis, and number of MTX applications. Results: One hundred and eight children were studied, 22 females (38\%) and 36 males (62\%), ages 1 to14 years. The incidence of nephrotoxicity was $5.8 \%$ in 238 events of MTX administration. The children in the group with nephrotoxicity were older (average age $9.5 \mathrm{vs} 5, \mathrm{p}=0.036$ ), had higher baseline creatinine $(0.5 \mathrm{mg} / \mathrm{dL} \mathrm{vs} 0.4 \mathrm{mg} / \mathrm{dL} \mathrm{p}=0.006)$, and had lower baseline hemoglobin $(10.1 \mathrm{~g} / \mathrm{dL}$ vs $11.3 \mathrm{~g} / \mathrm{dL}, \mathrm{p}=0.034)$. Mucositis was associated with nephrotoxicity with OR $1395 \%$ CI $4-42, \mathrm{p}<0.001$. A cut-off value for creatinine of $0.44 \mathrm{mg} / \mathrm{dL}$ (AUC of $68 \%$ ) and an age of 8 years (AUC of $64 \%$ ) were identified for risk of nephrotoxicity. Conclusions: The incidence of MTX nephrotoxicity in children with ALL was $5.8 \%$, with a high association with mucositis. The risk is greater for children older than 8 years and baseline creatinine higher than $0.44 \mathrm{mg} / \mathrm{dL}$.
\end{abstract}

\section{Hosted file}

Main text.docx available at https://authorea.com/users/437027/articles/538951-age-andbaseline-creatinine-as-risk-factors-for-methotrexate-nephrotoxicity-in-children-withacute-lymphoblastic-leukemia-in-resource-limited-countries

\section{Hosted file}

TABLE 1 .docx available at https://authorea.com/users/437027/articles/538951-age-andbaseline-creatinine-as-risk-factors-for-methotrexate-nephrotoxicity-in-children-withacute-lymphoblastic-leukemia-in-resource-limited-countries 
Graphic 1. Empirical ROC curve of acute kidney injury and basal creatinine

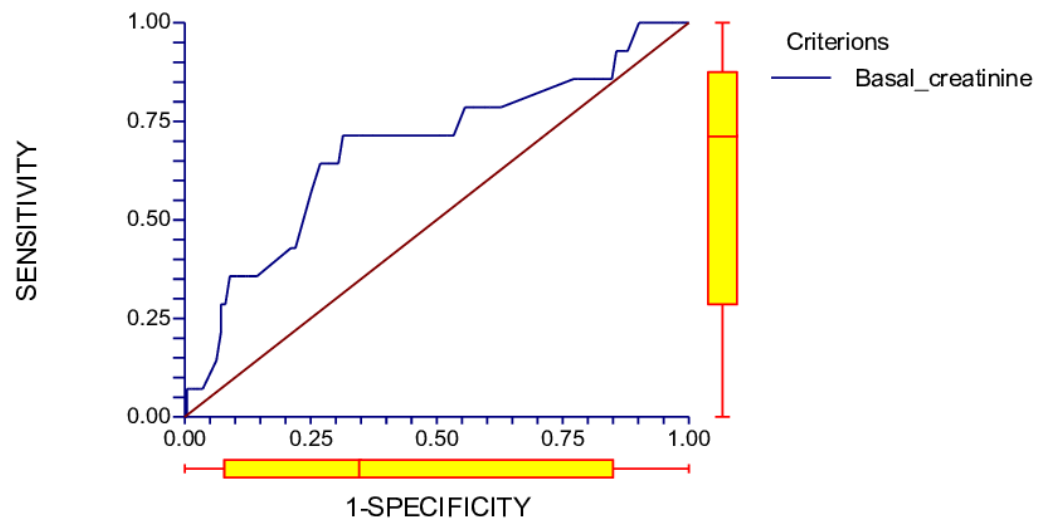

Area under the curve $68 \%$. For an acute kidney injury incidence of $6 \%$, the creatinine cut-off point of $0.44 \mathrm{mg} / \mathrm{dl}$ has a sensitivity of $71 \%$, a specificity of $69 \%$ and a likelihood ratio of $2.2 \%$.

\section{Graphic 2. Empirical ROC curve of acute kidney injury and age}

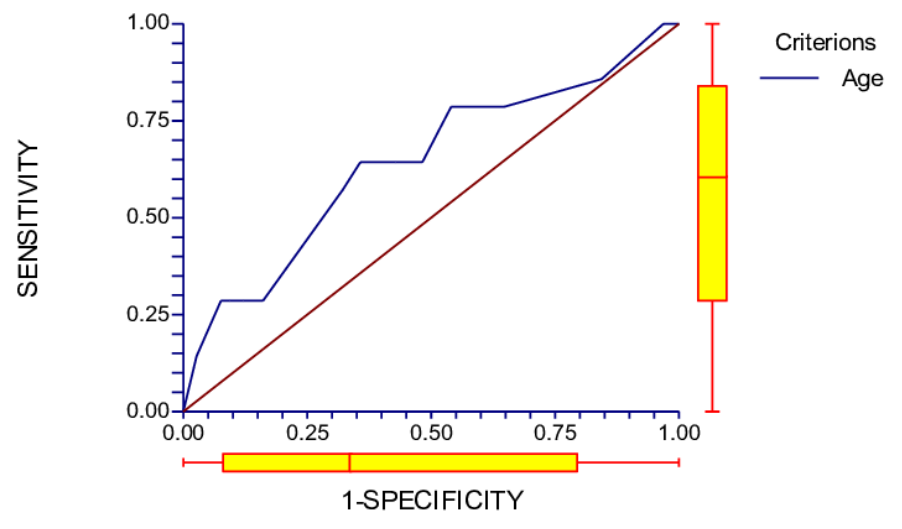

Area under the curve $64 \%$. For an acute kidney injury incidence of $6 \%$, the age cutoff point of 8 years has a sensitivity of $64 \%$, a specificity of $64 \%$ and a likelihood ratio of $1.8 \%$. 